\title{
A ecologia digital argumentativa: possibilidades e perspectivas para uma análise retórica da argumentação multimodal
}

\author{
Rodrigo SEIXAS (D)
}

ఠ

Universidade Federal de Goiás (UFG)

OPEN ACCESS

\section{EDITADO POR \\ - Isabel C. Michelan de Azevedo (UFS) \\ - Paulo R. Gonçalves-Segundo (USP) \\ - Fabrizio Macagno \\ (UNL)}

\section{AVALIADO POR}

- Josane Daniela Freitas Pinto (UEPA)

- Rui Grácio

(Grácio Editor)

DATAS

- Recebido: 15/09/2021

- Aceito: 15/11/2021

- Publicado: 07/12/2021

\section{COMO CITAR}

Seixas, R. (2021). A ecologia digital argumentativa: possibilidades e perspectivas para uma análise retórica da argumentação multimodal. Revista da Abralin, v. 20, n. 3, p. 918-937, 2021.

\section{RESUMO}

O objetivo deste artigo é o de apresentar algumas perspectivas para o estudo da argumentação digital, isto é, possibilidades de pensá-la, aproveitando alguns dispositivos retórico-discursivos de análise, tais como a doxa, em sua relação com a memória (tecno)discursiva e o interdiscurso, e, ao mesmo tempo, reconfigurando-os devido às especificidades impostas pelo espaço digital, em especial o espaço Web 2.0. Diante da profusão de textos multimodais próprios das redes sociais, lançaremos algumas luzes para a análise de textos nativo digital, multimodais, compostos por algumas publicações do Instagram, reunidas sob as tags \#forabolsonaro e \#impeachmentbolsonaro, no contexto que envolveu, antes e depois, as manifestações do 7 de setembro. Interessou-nos, em específico, a construção dos posicionamentos dos sujeitos, autores dos (re)publicações, a partir de uma perspectiva de análise retórico-discursiva que toma de empréstimo algumas contribuições teóricas de abordagens retórico-discursivas como as de Angenot (2008), Meyer (2008) e Seixas (2019). Chegamos às considerações, a partir dessa empreitada, que - em termos teórico, metodológico e analítico - é possível proceder a uma análise retórico-discursiva no espaço digital, valendo-se de elementos de análise já consagrados na retórica e na análise do discurso, desde que sejam reconfigurados e recondicionados às especificidades do discurso digital, tal como defende Paveau (2021). 


\section{REVISTA DA ABRALIN}

\section{ABSTRACT}

The aim of this article is to present perspectives for the study of digital argumentation, that is, some possibilities to think about it, taking advantage of some rhetorical-discursive analysis devices, such as doxa, in its relationship with (techno)discursive memory and the interdiscourse, and, at the same time, reconfiguring them due to the specificities imposed by the digital space (Web 2.0). Given the profusion of multimodal texts typical of social networks, we will shed some light for the analysis of digital native texts, composed of some Instagram publications, gathered under the tags \#forabolsonaro and \#impeachmentbolsonaro, in the context that involved, before and after, the September $7^{\text {th }}$ protests. We were specifically interested in the construction of the positions of the subjects, authors of (re)publications, from a perspective of rhetorical-discursive analysis that borrows some theoretical contributions from rhetorical-discursive approaches such as those of Angenot (2008), Meyer (2008) and Seixas (2019). We arrived at the considerations, from this undertaking, that is possible to carry out a rhetorical-discursive analysis in the digital space, drawing on elements of analysis already enshrined in rhetoric and discourse analysis, since that they are reconfigured and reconditioned to the specificities of the digital discourse, as defended by Paveau (2021).

\section{PALAVRAS-CHAVE}

Argumentação. Multimodalidade. Discurso digital. Retórica. Doxa.

\section{KEYWORDS}

Argumentation. Multimodality. Digital discourse. Rhetoric. Doxa.

\section{Introdução}

"Uma imagem vale mais do que mil palavras". Esse é um adágio popular muito presente em nossa doxa e que, sem dúvidas, parece corresponder, em muitos momentos, com a realidade, afinal há mesmo imagens que nos impactam, nos influenciam e geram efeitos em nós sem a necessidade de qualquer palavra. Temos visto, nos últimos tempos, sobretudo nas redes sociais, uma diversidade de imagens, ou de textos sincréticos, multimodais, portanto, por meio dos quais os usuários se posicionam, expõem sua opinião, manifestam seus valores etc. Nesse sentido, podemos, em certa medida, falar de um novo momento argumentativo, em que não mais a linguagem verbal é necessariamente 


\section{REVISTA DA ABRALIN}

predominante, mas trabalha em cooperação com outros tipos de linguagem para a construção dos mais variados sentidos na interação.

De fato, a multimodalidade, se efetivamente não foi um fenômeno inaugurado pela Internet, passa a ganhar, inegavelmente, novos contornos com o surgimento da Web 2.0 e suas redes sociais. Isso porque, na medida em que tais redes colaboraram para uma ainda maior multiplicidade e complexidade da interação social, devido à dinamicidade que lhes são próprias, elas fazem circular sentidos por meio de uma variedade de códigos semiológicos (CHARAUDEAU, 2001).

É todavia também verdade que os estudos de argumentação, durante muito tempo, centraramse nos fenômenos de persuasão e influência possibilitados pelo jogo da linguagem verbal. A retórica, por exemplo, nasce numa perspectiva verbal (oralizada, primeiramente, e depois absorvendo também o texto escrito ${ }^{1}$ ). No entanto, como todo saber que evolui com as novas exigências que a história, as sociedades e suas interações apresentam, a retórica tem igualmente se preocupado em expandir os seus horizontes de análise para além da linguagem verbal, absorvendo, já há um tempo, a linguagem imagética e podendo absorver, em tempos atuais, também as variedades semiológicas digitais.

Paveau (2021, p. 27) considera, igualmente, que o uso das tecnologias digitais, da internet e dos objetos conectados "estão sendo progressivamente integrados a nossas existências" e, não diferentemente, tem impactado não só na forma com a qual os discursos circulam em sociedade, mas também na forma com a qual eles são construídos e interpretados pelos sujeitos desse novo espaço digital. Passamos a falar não mais apenas de discursos, mas de "tecnodiscursos ${ }^{2 "}$, movimento que significa não só uma adaptação teórico-metodológica, mas também algumas reconsiderações epistemológicas próprias a um novo mundo conceitual.

Diante disso, veremos, neste artigo, formas para se pensar a argumentação dentro de uma perspectiva de análise retórico-discursiva multimodal, tomando de empréstimo algumas perspectivas teóricas de abordagens retórico-discursivas como as de Angenot (2008), Meyer (2008) e Seixas (2019). Tendo em vista à vasta gama de possibilidades e de elementos metodológicos para a análise argumentativa, adotaremos a postura de analisar, retoricamente, os posicionamentos dos sujeitos autores dos textos multimodais (re)publicados na rede social Instagram, buscando evidenciar a doxa (ou as doxai) que sustentam tais posicionamentos. Em seguida, procederemos a uma breve análise de alguns posts, a fim de identificar certos fenômenos discursivo-argumentativos, como a reefetuação de memórias (tecno)discursivas possibilitadas pelo interdiscurso.

O corpus de análise deste artigo é constituído por textos nativo digital, multimodais, compostos por algumas publicações do Instagram, reunidas sob as tags \#forabolsonaro e \#impeachmentbolsonaro, no contexto dos distintos discursos empreendidos no evento "Impeachment de Bolsonaro", em seus distintos episódios, como as "manifestações do 7 de setembro". A coleta dos dados se deu, portanto, com posts no decorrer do mês de setembro, dias antes e dias após essa célebre data que marca a independência do Brasil, obedecendo apenas a critérios multimodais - isto é, existência de

\footnotetext{
${ }^{1}$ Muito embora possamos falar, mas ainda de modo muito incipiente, em análise retórica de gestos e de prosódia.

${ }^{2}$ Além de outros tantos conceitos que, nessa realidade do discurso digital, passam a adotar o prefixo "tecno".
} 


\section{REVISTA DA ABRALIN}

sincretismo plurissemiótico - e, entre eles, o de serem posts obtendo o gênero "charge", por considerar tal gênero frutífero para posicionamentos críticos e ideológicos no terreno do domínio político-discursivo.

Pretendemos, em suma, apresentar algumas perspectivas para o estudo da argumentação digital, possiblidades de pensá-la, aproveitando os dispositivos retórico-discursivos de análise e, ao mesmo tempo, reconfigurando-os devido às especificidades impostas pelo digital. Não queremos aqui lançar uma abordagem de análise, mas sim discutir como é possível estudar os fenômenos argumentativos multimodais que ocorrem nesses espaços, em especial, nas redes sociais (Web 2.0), contribuindo para o avanço dos estudos argumentativos em contextos cada vez mais frequentes, e mesmo imperantes, em nosso cotidiano.

\section{O espaço público digital e a argumentação:}

\section{A nova Ágora?}

Tem se tornado cada vez mais frequente falar em "espaço público digital" ou em conceitos correlatos. Seixas e Nascimento (2021), por exemplo, apropriaram-se dessa noção para pensar a constituição do que consideraram um evento polêmico na rede social Twitter: uma fala do deputado federal Marcelo Freixo pedindo o impeachment de Bolsonaro. Sem dúvidas, são crescentes as inquietações a respeito de uma eventual possiblidade de impeachment e o evento "Impeachment de Bolsonaro" passa a ser frequentemente editado com novos eventos polêmicos, como o das "Manifestações do 7 de setembro", no qual Bolsonaro e boa parte de seus apoiadores tentaram fazer valer um golpe de Estado.

Ora, segundo eles, na esteira de Moirand (2014), os eventos não existem per se, mas são configurados discursivamente e, inclusive, seus sentidos podem ser disputados por meio de embates polêmicos no espaço público. Isso ocorre ainda mais frequentemente no espaço público digital, e de forma mais "democratizada", tendo em vista que, se antes a palavra pública ocorria em lugares institucionais físicos, a partir do surgimento da Web 2.0 - "web social ou participativa [...]", "web das redes sociais e do compartilhamento multimidiático" (PAVEAU, 2021, p. 35) -, as discussões ganharam a cena digital como um todo.

Seixas e Nascimento (2021) relembram que a política tem estado, nos últimos anos, bastante presente nas redes sociais e estas foram mesmo apontadas, em parte, como responsáveis pelas eleições de Donald Trump, nos EUA, em 2016, e de Jair Bolsonaro, em 2018, no Brasil. Por ter uma configuração comunicativa que favorece a disseminação da informação (seja ela falsa ou verdadeira), pela condição de espalhamento (spreadability) própria das redes sociais (ZAPPAVIGNA, 2015), o Twitter favorece a replicação de discursos políticos, inclusive polêmicos, que reforçam aspectos ideológicos, identitários, de determinados grupos.

Por essa razão, há quem pense esse espaço digital como uma nova Ágora, posto que se vê, nessas redes, o surgimento de novas institucionalidades para o uso da palavra. Se na Grécia Antiga, a liberdade 


\section{REVISTA DA ABRALIN}

da palavra no espaço público era de direito restrito dos considerados cidadãos gregos -, hoje ela é franqueada, com infinita maior liberdade, para todas as pessoas com acesso à Internet, dando voz a quem, antes, não a possuía. Assim também defendem Dutra e Oliveira (2018), para quem a comparação se mostra pertinente sobretudo por ter sido a Ágora o lugar de desenvolvimento comunicativo da polis. Ancorados nos pressupostos de Lévy (1999), tais autores consideram que o atual momento da comunicação midiática (com o surgimento dessas novas mídias da Web 2.0) favorece o surgimento de uma ciberdemocracia, isto é, "uma democracia que tem como cenário principal de representatividade as trocas comunicativas em mídias sociais digitais" (SEIXAS; NASCIMENTO, 2021, p. 2402).

De fato, Levy (1999), há algum tempo, já previa que o mundo se deslocava para uma era do "ciberespaço", isto é, o "espaço de comunicação aberto pela interconexão mundial dos computadores e das memórias dos computadores" (LÉVY, 1999, p. 92). Essa realidade gera, ainda segundo o autor, uma "cibercultura", própria de um universo sem centro nem linha diretriz, que se caracteriza pela variabilidade das relações de contato, de comunicação e de uso de informações (o que veremos mais a frente como "relacionalidade"). Levy (1999) afirma, a esse respeito, que o "ciberespaço", enquanto horizontal e livre, é um "sistema de sistemas", por meio do qual tudo pode ser compartilhado, em qualquer lugar, de distintas formas e modalidades (multimodalidade), para diferentes pessoas.

De fato, as redes sociais, pela sua força de replicação e pela liberdade do multicompartilhamento, permitem aos sujeitos o uso de diversas mídias e de diversos recursos semiológicos, entre os quais a imagem, os vídeos, os textos verbais etc., para interagirem e, também, para se posicionarem no espaço público digital. Essa nova realidade comunicativa impacta também nos meios com os quais os sujeitos se valem para interagir. Se entendemos, portanto, que a Web 2.0 se torna a nova Ágora, o modo com o qual as pessoas comunicam entre si deixa de ser aquele das configurações verbais, e mesmo gestuais, e passa a ser constituída por uma série de elementos próprios do digital, o que gera uma transformação das formas de cognição, numa espécie de "simbiose" entre o modo de pensar e agir humanos e o modo de pensar e agir da máquina.

O Instagram, por exemplo, tendo se consolidado como a rede social de fotos mais usada no Brasil e no mundo, passa também a ser utilizada, a exemplo do Twitter - e, inclusive, tomando-lhe de empréstimo alguns fenômenos, tais como as hashtags -, como o espaço público digital em que discussões políticas de tons variados e níveis de polemicidade distintos ganham a forma sincrética do diálogo de imagens e texto verbal, algo característico dessa rede social.

Diante desse cenário, é natural que se tenha uma reconfiguração sociodiscursiva, isto é, das formas de se comunicar e, consequentemente, das formas de narrar, argumentar, descrever etc. Paveau (2021), a propósito, estabelece uma dura crítica a respeito da postura de muitos teóricos, entre eles variados analistas de discurso, os quais, ao trabalhar com a materialidade discursiva em ambientes digitais, pensam-na a partir da configuração verbo-voco-visual tradicional, como se o espaço digital apenas fornecesse um suporte para a comunicação. Para ela, "a linguística parece neutralizar a máquina para transferir toda a responsabilidade da criação linguageira ao humano" (PAVEAU, 2021, p. 31). 


\section{REVISTA DA ABRALIN}

Segundo Merzeau (2009), com efeito, não se pode pensar a ascensão do digital como apenas uma nova codificação dos conteúdos, ou um novo canal de circulação. É, na verdade, "uma transformação do ambiente, que afeta as estruturas e as relações" (MERZEAU, 2009, p. 23). Levando sob essa perspectiva, o digital não apenas introduz novas possibilidades para a multimodalidade; na verdade, ela possibilita a própria revolução do multimodal (há quem fale de "revolução digital"), em que diversos elementos, humanos e não-humanos, devem ser levados em conta na constituição dos sentidos.

Sendo assim, pensar a argumentação nesse cenário, levando em consideração a Web, a máquina e os dispositivos tecnológicos apenas como suportes, desvirtua o princípio básico de uma análise que privilegia as condições reais de produção desse discurso, em seus mais variados e complexos aspectos. Não se trata apenas de um povoamento dos seres humanos no mundo da máquina, na medida em que "são as máquinas e seus programadores que permitem que as produções linguísticas, fruto da intencionalidade dos sujeitos, sejam realizadas e adquiram uma existência" (PAVEAU, 2021, p. 33). Assim, passaremos a pensar, a partir disso, a questão da multimodalidade, tão presente nesse espaço digital, por meio de uma perspectiva retórica que privilegie a análise argumentativa de discursos digitais e, portanto, multimodais.

\section{A multimodalidade e as retóricas}

O trabalho com a multimodalidade não é um ativo exclusivo da análise do discurso e da argumentação. Na verdade, o estudo de Roland Barthes sobre a Retórica da Imagem (Rhétorique de l'image), publicado na revista Communications, em 1964, mostra a sua preocupação com os sentidos advindos de uma relação semiológica para além da linguística. A semiótica, desde a sua origem com Charles Pierce, até as demais incursões feitas por Algirdas Greimas, por exemplo, e tantos outros, traz para o centro da discussão a existência de signos que extrapolam o linguístico e que convergem, num todo, para a construção do sentido.

Estamos, nesse ponto, diante das velhas distinções estabelecidas pelas variadas concepções de linguagem, as quais, apesar de suas variabilidades, centraram-se, em maior ou menor medida, na linguagem enquanto fenômeno verbal, sinônimo, portanto, de "língua". Os estudos semióticos, por sua vez, ao preverem, tal como defendia Hjelmslev, a existência de um "plano do conteúdo" - responsável pelo percurso gerativo do sentido - e um "plano da expressão" - "a(s) linguagem(ns) que veicula(m) o conteúdo" (LARA, 2013, p. 194) -, abre a disponibilidade, no domínio deste último, ao estudo de linguagens "paraverbais", tal como a imagem, fixa ou em movimento, o som, as cores etc.

Essas mudanças, para além de teórico-metodológicas, implicam também reformas epistemológicas importantes, sobretudo no que diz respeito ao estatuto do sujeito enquanto produtor/interpretador de sentido. Se entendemos aqui, em uma perspectiva discursivo-argumentativa, o sujeito como "cindido", portador de intencionalidade, mas apenas parcialmente consciente dos caminhos do sentido que provoca ou dos quais é parte - um sujeito atravessado pela palavra do outro e "condicionado pelos possíveis de seu tempo" (AMOSSY, 2020) -, compreenderemos que tais "possíveis" 


\section{REVISTA DA ABRALIN}

dizem respeito, também, não só à doxa, isto é, ao conjunto de crenças, tampouco apenas aos valores que sustentam as suas posições no discurso, mas também às restrições de configuração do "fazer sentido". Tais restrições, num espaço multimodal, extrapolam as limitações da linguagem verbal.

O sujeito da era multimodal é, por assim dizer, múltiplo, porque múltiplas são as suas possibilidades de interação. A multimodalidade pode ser entendida como a qualidade de um produto ou evento semiótico construído com base no emprego de diversos modos, os quais se relacionam e convergem na produção de sentido (KRESS; VAN LEEUVEN, 2001) e, sendo assim, o sujeito multimodal é aquele capaz de ler e produzir sentidos em modos vários, desde os elementos linguísticos até os aspectos imagético/icônicos ${ }^{3}$. Nesse contexto de novas interações, tendo também novas formas de escritores e leitores - "escrileitores", na perspectiva de Paveau (2021) -, a imagem, em sua relação sincrética com o texto verbal, passa também a ganhar cada vez mais espaço.

Para Gallinari (2013), a imagem pode ser compreendida naturalmente como um logos, tal como também o é a própria língua, podendo ser analisada igualmente, portanto, por meio de uma retórica. É possível, de fato, empreender uma análise retórica da imagem, levando-se em conta, para além dos aspectos conotativos e figurativos do logos imagético, a construção de ethos e de pathos, afinal as imagens, para além de representações, são, antes de tudo, meios eficazes de influência, seja para persuadir acerca de algum caráter ou por meio de certa imagem de si e do outro construídas pelo orador (ethos), seja pelo conjunto de emoções potencialmente persuasivas suscitadas no auditório (pathos).

Queremos acrescentar que, além das dimensões retóricas supramencionadas, é possível pensar na imagem a partir de uma análise da doxa, isto é, do conjunto de opiniões de um sujeito, o qual, em seu discurso, ao se posicionar a respeito de alguma coisa, manifesta no mundo os valores que estruturam sua opinião, suas crenças, suas ideias etc. (SEIXAS, 2019). Ademais, uma imagem, assim como qualquer outro tipo de linguagem, ancora-se na história para significar, desperta sentidos, dialoga com outros discursos, de outras linguagens, aciona memórias (como veremos), pois não se trata mais de uma mera representação ou código semiótico/semiológico, mas sim do próprio discurso que emerge em suas realizações. Charaudeau (2001), a esse respeito, afirma:

O discurso não deve ser assimilado à expressão verbal da linguagem. A linguagem, mesmo sendo dominante no conjunto das manifestações linguageiras, corresponde a um certo código semiológico, isto é, a um conjunto estruturado de signos formais, do mesmo modo, por exemplo, que o código gestual (linguagem do gesto) ou o código icônico (linguagem da imagem). O discurso ultrapassa os códigos de manifestação linguageira na medida em que é o lugar da encenação da significação, sendo que pode utilizar, conforme seus fins, um ou vários códigos semiológicos. [...] é preciso que fique claro que toda encenação discursiva depende das características desses códigos e de todos os códigos nela envolvidos (CHARAUDEAU, 2001, p. 25-26).

\footnotetext{
${ }^{3}$ Fala-se, a propósito, de "letramento icônico", como afirma Mendes (2013, p. 125), assim como de "letramento digital" (GILSTER, 1997).
} 


\section{REVISTA DA ABRALIN}

O discurso, por assim dizer, independe do código semiológico pelo qual é veiculado ${ }^{4}$ : Há discurso na imagem, há discurso no som, há discurso nas cores etc. A propósito, tomando como referências tais perspectivas multisemióticas e retóricas, a análise do discurso vem aumentando seu escopo teórico-metodológico nos últimos anos, ao propor meios de análise da interação texto verbal-imagem, ou ainda entre o texto verbal e outras semioses. Essa foi a razão de existência da obra Imagem e Discurso, publicada pelo grupo NETII da UFMG, em 2013, na qual diversos pesquisadores problematizam o lugar da imagem nas AD’s e propõem modalidades de análise e estudo. Nessa esteira, torna-se possível pensar em múltiplas possibilidades analíticas, entre elas a de análise retórica - ou argumentativa - multimodal, se entendemos que a retórica, para além de uma "arte da persuasão" (ARISTÓTELES), implica relações mais amplas de influência (AMOSSY, 2020; PERELMAN e OLBRECHTS-TYTECA, 2005). Nessa esteira, Mendes (2013) afirma que as imagens "têm a faculdade de nos comover, nos indignar, nos fazer rir, nos persuadir, nos distrair, nos fazer fantasiar [...], enfim, são parte integrante de nossa paisagem cotidiana [...]" (MENDES, 2013, p. 13).

Não pretendemos, no entanto, propor métodos ou categorias de análise de imagens. Consideramos, assim como Mendes (2013), que existem algumas propostas, de outros domínios (semiótica, comunicação, audiovisual, tecnologia etc.), capazes de fornecer meios para assessorar uma análise discursivo-argumentativa de textos sincréticos/multimodais. Queremos apenas chamar a atenção, a partir de uma perspectiva retórico-argumentativa do discurso, para a possiblidade de usar elementos da retórica, seus conceitos e pressupostos, a fim de compreender como um discurso pode circular nas redes sociais, atravessando diversas linguagens e constituindo sentidos potencialmente persuasivos ainda mais fortes do que constituiriam se fosse apenas usada, para tanto, a linguagem verbal.

Todavia, é necessário salientar que pensar a argumentação multimodal, nesse cenário, implica compreender que, para além da relação sincrética texto verbal-imagem, há ainda outros elementos que devem/podem ser levados em consideração e que são próprios das redes sociais e da Web 2.0. Dito de outra maneira, apesar da profusão de imagens e textos sincréticos nas redes, há ainda uma falta de compreensão a respeito dos elementos que configuram o ambiente digital e suas especificidades, as quais consideramos ser importantes para uma análise argumentativa que se preze multimodal.

\section{As relações no ambiente: a ecologia argumentativa.}

Com efeito, Paveau (2021) empreende sua crítica contra o que chama de "perspectiva dualista" da linguagem, isto é, que separa, ainda que sincreticamente instituídos, o texto verbal - linguístico, portanto - do texto extralinguístico, não verbal. Segundo a analista de discurso, tal perspectiva assume uma feição "logocêntrica" e deve ser repensada se temos a intenção de analisar discursos

\footnotetext{
${ }^{4}$ O que não significa que tais "códigos semiológicos" não estabeleçam suas restrições às formas de discurso e, também, à própria construção do sentido, como veremos logo adiante.
} 


\section{REVISTA DA ABRALIN}

digitais. Essa atitude passa pelo conceito de "ambiente" e, também, em sua consequência, pelo conceito de "ecologia discursiva".

O "ambiente", para Paveau (2021, p.49), é "o conjunto de dados humanos e não humanos no âmbito dos quais os discursos são elaborados". É, por assim dizer, uma alternativa crítica às noções de "contexto" e de "condições de produção do discurso" - consideradas por ela ainda dualistas - com o intuito de adotar uma perspectiva pós-dualista, a saber, que postula que "a consciência humana se manifesta no exterior da mente, especialmente nos objetos e nas técnicas", de maneira "distribuída", além de uma visão simétrica das materialidades linguageiras e de uma abordagem ecológica da produção de enunciados (PAVEAU, 2021, p. 49).

É importante ressaltar que a noção de "ambiente" não é nova, e consideramos que, na verdade, apesar das críticas estabelecidas pela linguista francesa às noções consagradas da Análise do Discurso (contexto e condições de produção), tal preterição tem maior relação com sua filiação teórica à abordagem cognitiva dos discursos, sobretudo dentro de uma perspectiva da cognição social e, de modo mais específico, da "cognição distribuída". Segundo Paveau,

\footnotetext{
o princípio de base é o da mente estendida (extended mind) e os processos cognitivos são descritos como "distribuídos" entre os agentes e seu ambiente, compreendendo este ao mesmo tempo os objetos e artefatos, mas também as estruturas sociais no sentido amplo. O sistema cognitivo não é mais o indivíduo, mas o conjunto dos agentes humanos, não humanos e sociais, e a unidade de observação e de análise é, assim, fortemente modificada em relação à cognição individual. [...] O ambiente não é mais considerado como um pano de fundo para a cognição, mas como um conjunto de "recursos ambientais" (PAVEAU, 2021, p. 50/51).
}

Em um ambiente discursivo, portanto, habitam não só enunciados, mas o próprio "conjunto do sistema no qual ele é produzido" (PAVEAU, 2021, p. 49), formando um ecossistema. A metáfora ambiental ainda persiste. Como vimos, Paveau (2021) fala de uma "ecologia do discurso", a saber, "uma abordagem da análise do discurso que toma como objeto não mais somente elementos linguageiros, mas o conjunto do ambiente nos quais eles se inscrevem" (PAVEAU, 2021, p.159). Nesse sentido, para a linguista, importa ao analista do discurso compreender as diferentes semioses dispostas em um ambiente de elementos compósitos por natureza. Esse ambiente compreende como produtores de sentido não só os agentes e suas manifestações verbais, ou mesmo com suas manifestações icônicas/imagéticas, mas, de maneira profundamente atrelada, devem ser levados em conta os gestos de "escrileitura do usuário inseparáveis dos enunciados (clicar, rolar, tocar)" (PAVEAU, 2021, p. 159).

Os gestos de "escrileitura", a propósito, revelam a "relacionalidade" própria do ambiente digital, pela qual qualquer discurso digital mantém

relação com outros tecnodiscursos em decorrência da estrutura hipertextual; relação com os aparelhos em decorrência da natureza compósita dos tecnodiscursos, literalmente coproduzidos na máquina; relação com os escritores e escrileitores, que passa pela subjetividade da configuração das interfaces de escrita e de leitura, e que torna os tecnodiscursos ideodigitais, isto é, dependentes do ponto de vista único do internauta (PAVEAU, 2021, p. 311). 


\section{REVISTA DA ABRALIN}

Nesse sentido, faz parte da relacionalidade desse ambiente a própria característica hipertextual da Internet e, ainda mais, da Web 2.0. Tais hipertextos se dão por meio de links, isto é, endereços de passagem, que ligam um lugar a outro no espaço digital. As hashtags, por exemplo, são hiperlinks que, ao serem clicados, levam a um agrupamento de outras publicações em que elas tenham sido publicadas, tanto no Twitter quanto no Instagram. Paveau (2021, p. 312) afirma que, se esses tecnodiscursos podem ser ligados, "então podem ser buscados, encontrados e redocumentarizados a partir da exploração dos links". Nesse caso, trata-se de sua função enquanto organizadora de metadados sociais (ZAPPAVIGNA, 2015), isto é, no sentido de que tais metadados são descriç̃es feitas pelos usuários que marcam, etiquetam, o conteúdo/objetivo de seu post ou tweet. Nesse sentido, afirmam Seixas e Nascimento (2021), a hashtag funciona, em primeiro aspecto, como um recurso de agregacão de dados acerca de um determinado assunto ou evento. A seguir, por exemplo, temos o recurso de tags do Instagram reunindo, no momento da coleta empreendida por este analista, todos os posts em que foram usadas as hashtags \#forabolsonaro nas publicações:

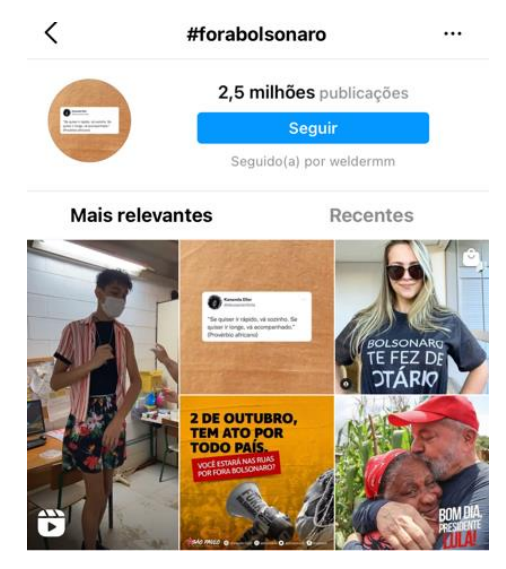

FIGURA 1 - Hashtags \#forabolsonaro no Instagram

Fonte: Instagram.

É possível perceber, na Figura 1, que há 2,5 milhões de publicações, no Instagram, em que foram publicadas a \#forabolsonaro. O conteúdo dessas postagens, no entanto, bem como a modalidade semiológica utilizada para a comunicação, são as mais variadas. Como dito, trata-se esse recurso, portanto, apenas de um grande organizador de metadados, a partir do critério por hashtag.

As hashtags, no entanto, possuem também outras funções. Seixas e Nascimento (2021), como já dissemos, afirmam que elas exercem uma importante função cognitiva na própria construção e/ou manutenção de eventos argumentativos, em especial os polêmicos. Nesse sentido, o evento "Impeachment de Bolsonaro", crescente nos últimos meses, passa a estar cada vez mais presente nas redes sociais, sendo alimentado por manifestações políticas nas distintas formas de hashtags acima colocadas e revelando diferentes argumentações, em diferentes modalidades. A imensa possibilidade de recursos argumentativos de distintas modalidades, e a ligação existente entre eles, torna mesmo possível pensar em uma ecologia argumentativa que, por meio da "relacionalidade" das redes sociais, 


\section{REVISTA DA ABRALIN}

favorece o espalhamento (spreadability) (ZAPPAVIGNA, 2015) das publicações e enriquecem os sentidos instaurados no espaço público digital.

A partir dessa perspectiva, é possível traçar um paralelo com a argumentação e compreender a existência de uma ecologia argumentativa propriamente dita, na medida em que as diferentes semioses colaboram para a constituição de sentidos persuasivos, ainda que potenciais. Se tomamos por exemplo o Twitter e o Instagram, teremos a possibilidade de um usuário, por meio do compartilhamento de vídeos de outras redes sociais, fazer um comentário e tuitá-lo/postá-lo, fechando seu tuite/post com uma determinada hashtag, seja como forma de enquadramento temático mais amplo ou mesmo como uma espécie de protesto (SEIXAS; NASCIMENTO, 2021).

Seixas e Nascimento (2021), por exemplo, ao proceder a um estudo retórico-argumentativo de um evento polêmico no espaço digital do Twitter, analisaram a hashtag \#impeachmentoumorte. Foi possível perceber, nesse estudo, que não só os sentidos foram advindos do conteúdo do enunciado em si - chamado por eles de enunciados-matriz ${ }^{5}$ - mas, sobretudo, das características próprias dessa rede social, em que as hashtags se tornam não só organizadoras de metadados e hiperlinks, mas também, e cada vez mais frequentemente, enunciados argumentativos, tal como cartazes de militância política que favorecem comunidades identitárias (SEIXAS; NASCIMENTO, 2021), em um fenômeno chamado por Husson (2016) de "militantismo 2.0". Nessa perspectiva, ela afirma que as hashtags tornam-se, no fim das contas, palavras-argumento, isto é, palavras que condensam, em sua enunciação, "conteúdo metadiscursivo denso que funciona como apelos a pré-discursos [...] de ordem argumentativa" (HUSSON, 2016, p. 106, tradução nossa), constituindo-se etiquetas polêmicas.

Tais "pré-discursos" (PAVEAU, 2013), dentro da perspectiva retórica em que nos inserimos, são entendidos como estruturantes da doxa, isto é, do conjunto de saberes que fundamentam uma opinião e, portanto, um posicionamento. Vejamos:

\footnotetext{
${ }^{5}$ Os autores consideram os enunciados-matriz como aqueles que dão partida a um evento polêmico, isto é, aqueles que desencadeiam uma série de outros atos argumentativos e polêmicos em resposta, seja para com ele concordar ou para dele discordar (SEIXAS; NASCIMENTO, 2021).
} 


\section{REVISTA DA ABRALIN}

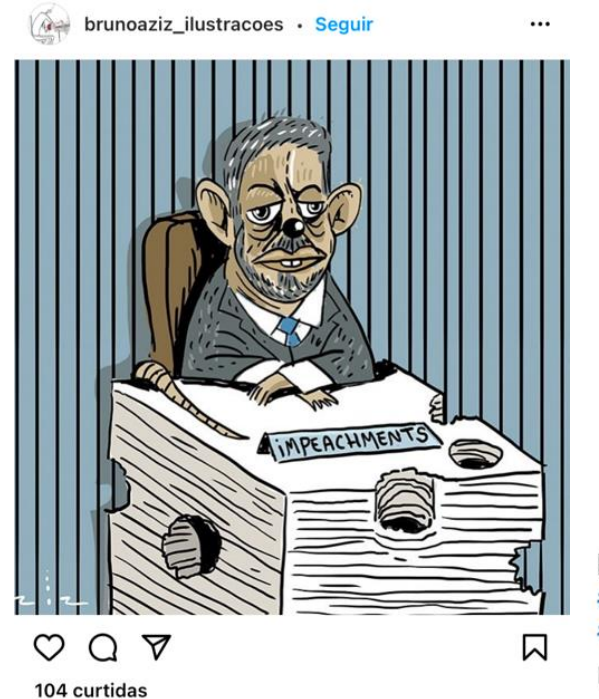

104 curtidas brunoaziz_ilustracoes Nome aos ratos: Arthur Lira. \#brasil \#impeachmentbolsonaro \#impeachment \#forabolsonarogenocida

Há 1 dia · Ver tradução

\section{FIGURA 2 - Post $\lg 1$ \\ Fonte: Instagram - @bruzoaziz_ilustracoes.}

No post acima, temos um texto sincrético, multimodal, com aparentemente apenas dois elementos semiológicos em jogo: o primeiro elemento seria a imagem, dominante nesse texto, constituída pela representação do deputado federal Arthur Lira (Progressistas-AL), presidente da Câmara dos Deputados, como um "rato comedor de pedidos de impeachment". Não precisamos de muito esforço interpretativo para entender que se trata, em primeiro lugar, de uma crítica humorada - característica comum às charges -, a respeito da falta de vontade do deputado em admitir o pedido de impeachment do presidente Jair Bolsonaro. Em segundo lugar, e mais importante, a imagem também nos remete à figura do "rato", a qual, no imaginário mundial, conota sujeira. No entanto, no imaginário brasileiro em específico, a representação do rato conota também, conforme o Dicionário Houaiss Online de Língua Portuguesa, uma "pessoa trapaceira, tratante" (RATO..., 2021). É mesmo possível unir as duas conotações, na medida em que se pode afirmar ser "sujo", no sentido figurativo, aquele que comete trapaças. Há, por assim dizer, uma doxa que sustenta tal representação imagética, um discurso a propósito dos "ratos" que estão no poder e que, para manterem seus benefícios e privilégios ilegais, lançam-se em negociações e relações escusas.

O segundo elemento semiológico é o texto verbal, em que temos, na imagem, de forma sincrética, a própria palavra "impeachments". Nesse caso, o texto verbal, por mais simples e elementar que pareça, possui função importante na definição e no esclarecimento dos sentidos, posto que poderiam ser quaisquer outros documentos a serem mordidos pelo "rato deputado". Ademais, a legenda colocada pelo autor do post, "Nome aos ratos: Arthur Lira", e também as hashtags escolhidas por ele (\#ImpeachmentBolsonaro, \#impeachment, \#forabolsonarogenocida), adicionam sentido à publicação e deixam clara a opinião do autor, evidenciando as doxai que sustentam tal posicionamento.

Manifestação semelhante ocorre no seguinte post: 


\section{REVISTA DA ABRALIN}

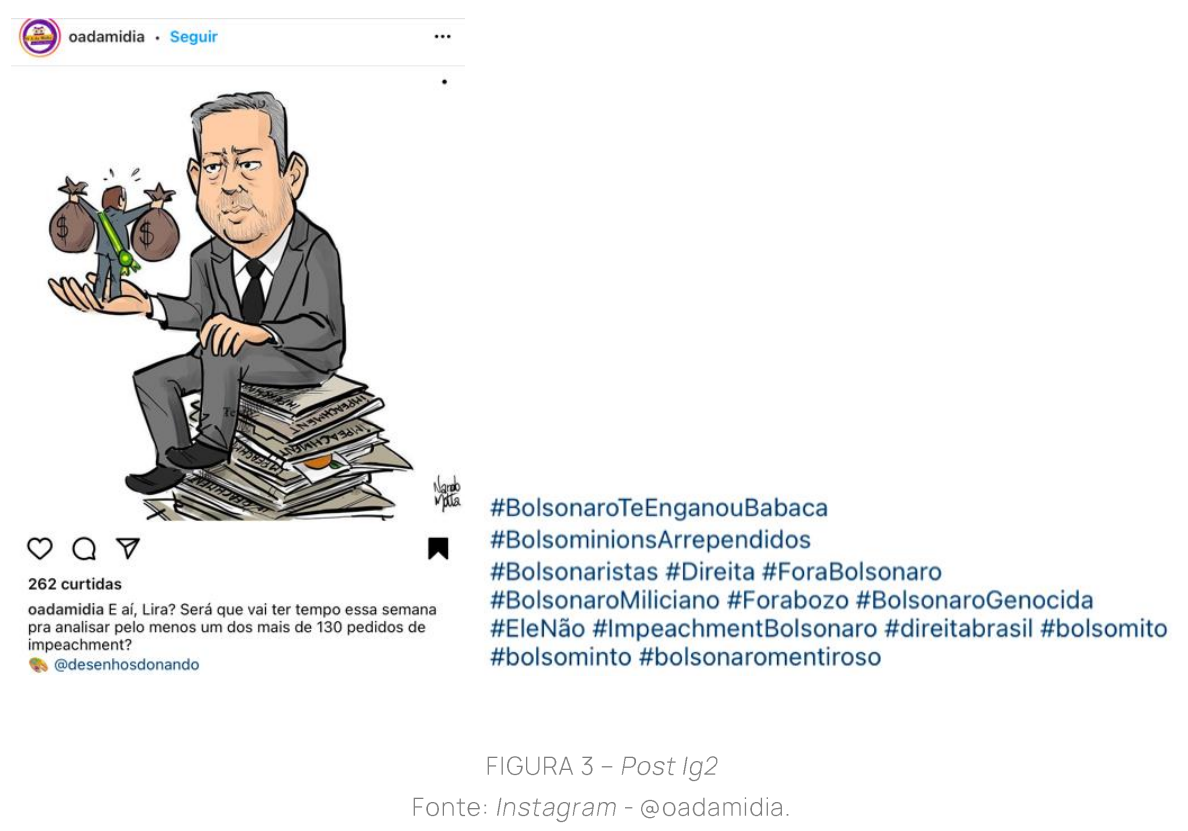

No caso da charge acima, de autoria de Nando Mota, temos um interdiscurso em operação, na medida em que existe um claro diálogo entre esse texto multimodal e o texto do Post Ig1. Há, no entanto, no Post Ig2 logo acima, um novo elemento imagético a ser levado em conta: o da representação do presidente Bolsonaro, em miniatura, segurando dois sacos de dinheiro. É possível, a esse respeito, ao menos duas inferências: a primeira, mais óbvia, a de que o deputado federal Arthur Lira tem decidido não admitir qualquer um dos 130 processos de impeachment porque foi supostamente comprado pelo presidente; a segunda inferência é a de que o Jair Bolsonaro - apequenado, pois em miniatura - está "nas mãos" do deputado Arthur Lira, o que argumenta uma dependência do governo Bolsonaro à vontade do deputado.

Assim como ocorrido no Post Ig1, o posicionamento do autor do Post Ig2 se torna ainda mais claro se tomamos como referência as hashtags atreladas, a saber, a mesma \#ForaBolsonaro e \#ImpeachmentBolsonaro, entre outras, figuram como posicionamentos claros do autor. Esse movimento é argumentativo, portanto, na medida em que estamos diante, assim como afirma Angenot (2008), de processos de "posicionamento", "justificação" desse posicionamento e "resistência" ao posicionamento do outro.

Ora, na medida em que é possível falar de uma multimodalidade argumentativa nessas redes sociais, consideramos que se torna igualmente possível pensar em uma breve análise retórica - como já iniciada, a propósito - dos discursos nesses ambientes. Partiremos, para tanto, de abordagens retórico-discursivas como as empreendidas por Angenot (2008) e Meyer (2008), em diálogo com algumas contribuições de Moirand (2014) e Paveau (2013; 2021). Como dissemos, o foco da análise se dará no sistema retórico da doxa, valendo-se, igualmente, de alguns conceitos analítico-discursivos que lhe fazem possível diálogo, tal como o de memória cognitivo-discursiva (e suas variações a partir da perspectiva do discurso digital) e de interdiscurso. 


\section{REVISTA DA ABRALIN}

\section{Uma breve análise retórica multimodal: nas tramas da doxa e da memória}

Entendemos a retórica, nesse momento, em uma integração conceitual entre a concepção de Meyer (2008) e a de Angenot (2008). Isso significa que, ao mesmo tempo em que a compreendemos como a "negociação de distâncias entre os sujeitos acerca de uma questão" (MEYER, 2008), também a compreendemos como o estudo dos posicionamentos admitidos, da justificação desses posicionamentos e da resistência ao posicionamento contrário (ANGENOT, 2008). No fim das contas, ambas as concepções, mutatis mutandis, aproximam-se substancialmente, na medida em que, ao falar em "negociação de distâncias", implica-se que existam posições tomadas e admitidas, problemáticas e polêmicas frequentemente, e que precisam ser negociadas porquanto constituem um problema para o acordo e para a convivência entre os diferentes sujeitos.

Entretanto, é importante salientar que a negociação de distâncias não significa apenas um esforço pelo acordo, ou pela persuasão. Na verdade, é possível falar também, segundo Meyer (2008), em distâncias que são majoradas propositadamente, porque interessa aos sujeitos da interação manterem-se polarizados com vistas ao fortalecimento de identidades políticas, como ocorre nos casos de polêmicas intensamente antagonizadas. Essa condição discursiva, ampliada sensivelmente pela configuração das redes sociais, possibilita o surgimento de posicionamentos e, portanto, de opiniões cada vez mais engajadas.

Estamos, nesse ponto, diante da doxa, a qual se coloca, afirma-nos Angenot (2008, p. 64), como o "o material da retórica", na medida em que consiste, como já expomos, num conjunto de saberes, crenças e opiniões admitidas por um indivíduo ou por uma coletividade. Apesar de o conceito não ser homogêneo (há distintas nuances em seu alcance epistemológico), tomaremos a compreensão de Seixas (2019), pela qual a doxa pode ser pensada como a manifestação do(s) sujeito(s) no mundo das coisas públicas, revelando, em tal movimento, os seus valores, ideologias, pensamentos, crenças etc. Nesse sentido, ela pode significar tanto o pensamento comum de um grupo, o senso comum, os estereótipos, clichês etc. - "elementos dóxicos", como pontua Amossy (2020), quanto as evidências partilhadas, as identidades de crença etc.

Tais identidades de crença, muitas vezes, são fortalecidas por meio de atividades cognitivo-discursivas, como a da reefetuação de memórias, isto é, de enunciados historicamente instituídos e que são frequentemente evocados com o fim de persuadir (ou manter persuadidos) os sujeitos de um grupo a respeito de uma questão (SEIXAS, 2019). Paveau (2021), a esse respeito, ancorada na concepção original de "memória discursiva" de Jean Jacques Courtine, afirma que "todo enunciado é assumido em múltiplas inscrições anteriores, concomitantes e também futuras, e delas tira seu sentido" (PAVEAU, 2021, p. 267). No entanto, levando-se em consideração as diversas particularidades do espaço público digital, dos recursos que as redes sociais permitem (inclusive, funcionando, no caso das hashtags, como elementos de memória), a linguista defende ser pertinente o uso do termo "memória tecnodiscursiva", pela qual entende como sendo uma 


\section{REVISTA DA ABRALIN}

memória desenvolvida em universos conectados, que amplia as capacidades da memória discursiva não equipada digitalmente, produz arquivos nativos inéditos em formas digitais nativas, ordena parcialmente a massa de dados discursivos on-line e constitui linhagens discursivas e formulações prévias para a elaboração dos discursos (PAVEAU, 2021, p. 267).

Ainda segundo a autora, essa memória tecnodiscursiva se baseia, entre outros fatores, justamente na "plurissemioticidade dos dados" (PAVEAU, 2021, p. 267), isto é, nas distintas modalidades semiológicas/semióticas presentes no discurso digital, conforme pudemos ver nos posts anteriormente apresentados e que poderemos perceber nos posts a seguir:

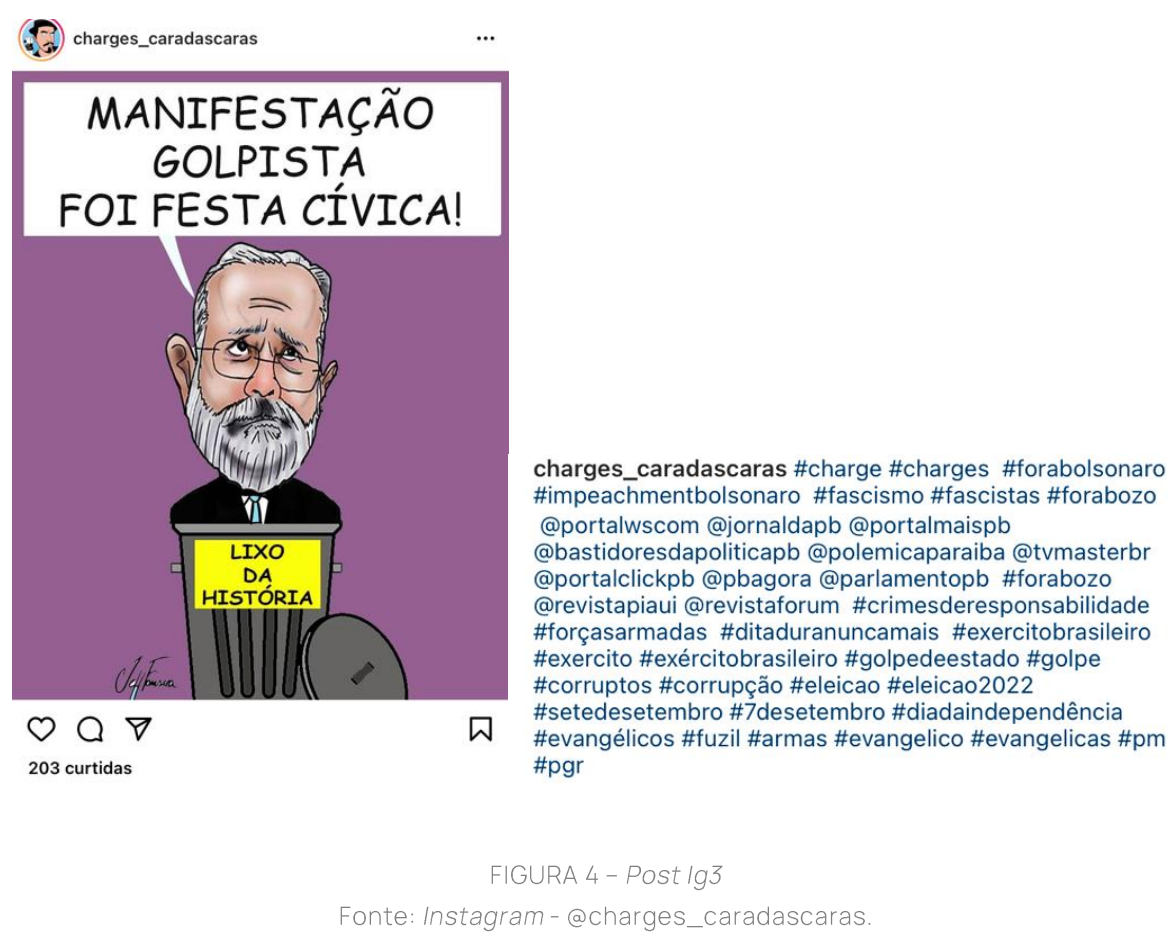

Na publicação acima, o chargista representa o procurador-geral da República (PGR) dentro de uma lata de lixo, etiquetada com os dizeres "Lixo da história". O ato em questão polemiza com a posição adotada pelo PGR frente às manifestações do 07 de setembro. Para compreender os sentidos argumentativos por detrás dessa charge, não basta conhecer o conteúdo da imagem ou ter a perspicácia de compreensão da intenção do autor com o uso de cada elemento icônico. Na verdade, é necessário compreender qual é o valor em se considerar uma manifestação - avaliada como de cunho "golpista" pela maior parte dos juristas (BRANDINO et al., 2021) - como "uma festa cívica".

Se voltarmos um pouco no tempo, por exemplo, conseguimos resgatar, pela memória discursiva do Golpe de 1964, o argumento das manifestações das mulheres na "Marcha da Família com Deus pela Liberdade" como ordeiras e "cívicas", tendo como um dos principais responsáveis pelos atos, inclusive, o grupo chamado "União Cívica Feminina" (UCF) (MOTTA, 2002). Após o 31 de março de 1964, afirma Chaves (2021), tais manifestações "cívicas" passam a ser chamadas de "festas", "comemorações", que "homenageavam" as Forças Armadas pela queda do governo Jango. Há, por assim 


\section{REVISTA DA ABRALIN}

dizer, um interdiscurso presente no texto do Post Ig3, que argumenta contra o presidente, atrelando as manifestações do 7 de setembro por ele orquestradas com os acontecimentos que prenunciaram a ditadura militar no Brasil, em 1964.

Outra vez, as hashtags são usadas como "palavras-argumento" e se alinham, no posicionamento adotado pelo autor da charge, na sua construção argumentativa. O uso da \#fascista, por exemplo, ajuda na construção dos sentidos pretendidos pelo autor em acusar uma tentativa do presidente com um golpe de Estado, o que fica claro pelas próprias \#golpe, \#golpedeestado, \#ditaduranuncamais etc. Todas as tecnopalavras, enquanto "palavras-argumento", convergem para a mesma conclusão de que o presidente comete crime de responsabilidade por atentar contra a democracia (há também a \#crimederesponsabilidade) e, portanto, deve ser retirado do cargo (\#ForaBolsonaro). O presidente, nesse sentido, deveria ser denunciado por um funcionário de Estado que, não sendo "de governo", deve trabalhar pelos interesses da República e não pelos do governo ou de seu chefe.

O discurso do "golpismo" de Bolsonaro também aparece em outro post de Instagram, coletado por meio da análise de tags:

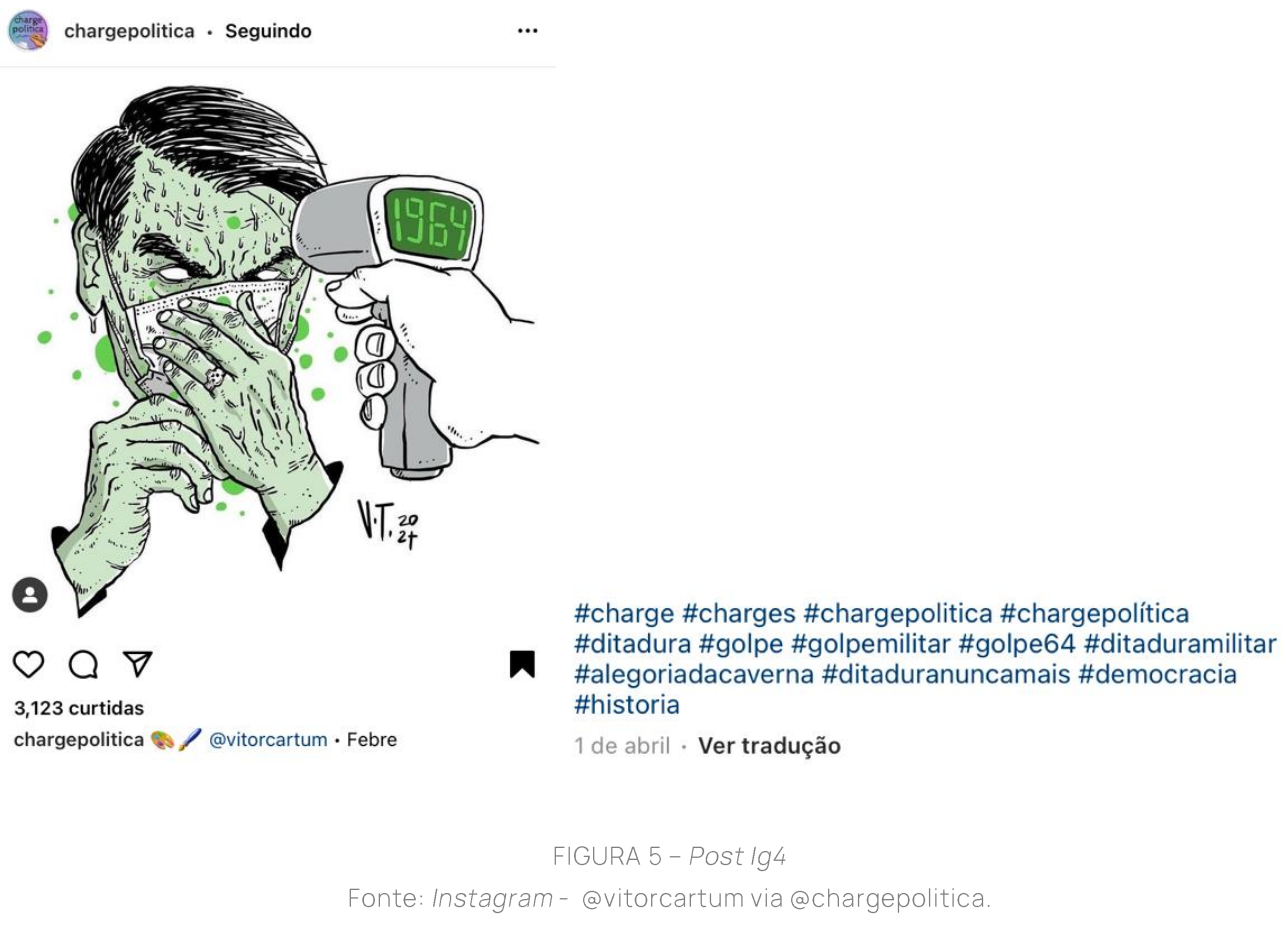

Percebamos que, no texto acima, há uma predominância indiscutível de elementos imagéticos ${ }^{6}$ mas, sem a existência do "1964" escrito dentro do medidor de temperatura, não seria possível

\footnotetext{
${ }^{6}$ Cabe comentar não ser aleatório o uso da cor verde para conotar a ideia de "doença”. Se dialogamos com a perspectiva semiótica de Greimas (1987), por exemplo, teremos na dimensão cromática um dos níveis de análise do percurso gerativo do plano de expressão. Mendes (2013), assim como Lara (2013), valem-se de contribuições de outros domínios para trabalhar com tais dimensões, entre outras (como a luz, os planos de enquadramento etc.). Sem dúvidas, há uma porção de outros elementos imagéticos a serem analisados na charge acima, cujos métodos, entretanto, não dispomos aqui neste trabalho, e tampouco é o nosso objetivo fazê-lo.
} 


\section{REVISTA DA ABRALIN}

empreender adequadamente os sentidos pretendidos pelo autor da charge, quais sejam: os de que, em tempos de pandemia, o maior vírus seria o que assola o presidente Bolsonaro, deixando-lhe doente - algo recuperável devido à cor verde do presidente e também das gotículas de suor que indicam mal-estar. Trata-se, portanto, da representação de um Bolsonaro doente (inclusive validado pela legenda "febre"), não pelo vírus do coronavirus, mas pelo vírus da ditadura, por meio de uma estratégia metafórica de transferência de valor coronavírus $\rightarrow$ ditadura, em que ambos são compreendidos dentro do campo discursivo da "doença". Seguem-se ao post as hashtags que fazem referência ao Golpe de 64, à ditadura e, inclusive, com a presença de tecnoenunciados do tipo \#ditaduranuncamais, uma clara manifestação de posicionamento.

Para ilustrar o funcionamento da doxa, da memória tecnodiscursiva e do interdiscurso, outro post se mostra interessante a uma breve análise:

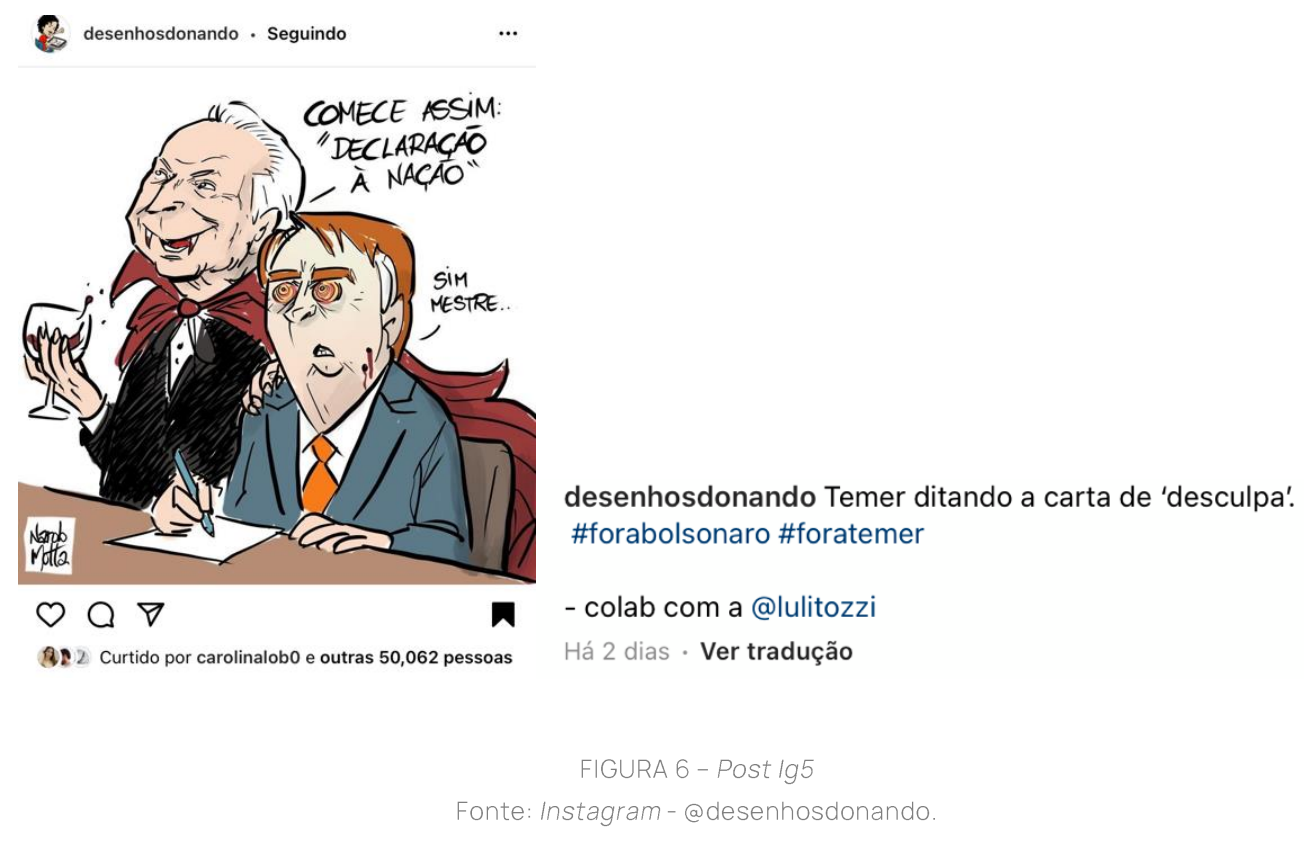

Na sequência do evento "Manifestação de 7 de setembro", com os desdobramentos contraproducentes dos atos golpistas (e, inclusive, com o considerado "fiasco" das manifestações), tivemos o ato do ex-presidente Michel Temer, em que ele aconselha o presidente Jair Bolsonaro a escrever uma carta (como está representado na charge), recuando de seus arroubos golpistas e se comprometendo a respeitar as instituições. O ex-presidente se pretende, a partir de tal ato, ser considerado um intermediador das relações institucionais entre os Poderes da República, então em grande conflito (sobretudo o Executivo, na pessoa do presidente, com o STF, órgão máximo do Judiciário).

Vemos que, na charge, temos, de um lado, a representação do ex-presidente Temer como um vampiro - apelido que ganhou, sobretudo entre os seus críticos - e, de outro, a representação do presidente Bolsonaro como estando hipnotizado, controlado, após ter sido mordido pelo "vampiro Temer". Há alguns elementos imagéticos/icônicos que convergem para essa inferência, como as marcas de mordida no pescoço do presidente, os olhos com conteúdo espiralado, indicando um 


\section{REVISTA DA ABRALIN}

estado de hipnose ou ausência de autocontrole, bem como a mão do ex-presidente Temer sobre os ombros do presidente Bolsonaro, indicando, igualmente, controle, domínio etc. Essa ideia de controle é confirmada pelos textos verbais, tanto o reputado a Temer ("Comece assim: declaração à nação"), quanto o reputado a Bolsonaro ("Sim mestre”...), os quais servem de suportes aos elementos imagéticos, dominantes nessa charge, como de costume no gênero.

Ora, sem dúvidas, tais elementos verbo-imagéticos, atrelados às hashtags \#forabolsonaro e \#foratemer, ativam, na memória tecnodiscursiva, eventos anteriores igualmente relacionados a uma doxa, ou ao conjunto de doxai, referentes ao "Golpe contra a ex-presidente Dilma Rousseff" em 2016. Isso porque o ex-presidente Michel Temer, ao escrever uma carta à então presidente Dilma, cujo conteúdo dizia respeito a uma insatisfação, à época, com relação ao seu papel presumidamente "decorativo" enquanto vice-presidente. A memória do Golpe de Dilma é, assim, evocada e reefetuada argumentativamente (SEIXAS, 2019) pelo autor da charge, trazendo novos sentidos (ou reforçando velhos) a respeito da tentativa de golpe de Bolsonaro ou, ainda, ao golpe em curso, o qual, segundo alguns críticos a esse governo, teve início justamente com o golpe contra a ex-presidente petista.

\section{Ainda algumas considerações finais}

A partir do que foi apresentado, fica a pergunta: podemos falar de uma retórica ou de uma argumentação digital? A resposta a essa pergunta é, inclusive, "retórica" e acreditamos ter sido respondida, positivamente, no decorrer deste artigo. Podemos afirmar que, ao entender a argumentação como um posicionamento, os discursos digitais nas redes sociais - não só nas charges, mas por meio de qualquer gênero que seja, e em qualquer tipo de modalidade semiológica - estão prenhes de opiniões políticas, posicionamentos a respeito de uma variedade de assuntos, inclusive sensíveis e polêmicos, que advogam em favor da tese de que tais redes sociais, de fato, colocam-se como a nova Ágora, o espaço público digital por excelência. A retórica, portanto, na medida em que tenha como seu material a(s) doxa/doxai, pode efetivamente servir para análises de argumentações nesse espaço.

Cabe dizer, em tempo, que esses posts permitem a interação entre os diferentes usuários, em uma troca que, a depender do perfil - se mais ou menos homogêneo - de seguidores de uma página ou conta, pode se constituir de maneira bastante dissensual e polêmica. Pode interessar ao analista de argumentação, por exemplo, em especial ao que se preocupa com interações polêmicas, analisar, junto aos textos sincréticos, multimodais publicados, as efetivas interações que ocorrem por meio dos comentários desses posts. Em se tratando de um tema político sensível e, portanto, de grande potencial para afetar emoções e reações mais enérgicas e conflituais, é comum esperar, e encontrar, posicionamentos de diferentes sujeitos/usuários, por meio dos quais entram em funcionamento as mais variadas, e tantas vezes antagônicas, doxai no discurso digital.

Dessa forma, sim, podemos falar de uma retórica/argumentação digital, na medida em que o espaço digital mobiliza os sujeitos a usarem de formas de cognição próprias desse espaço e, portanto, evoca novas variáveis de análise que devem ser levadas em conta pelo analista de 


\section{REVISTA DA ABRALIN}

argumentação. Trata-se, por assim dizer, de uma mesma retórica, em sua base - com os elementos que já lhe são característicos, como o ethos, o pathos, o logos, a doxa -, mas recobrindo, diante da multisemioticidade própria do discurso digital, as novas e variadas formas de configuração de sentido persuasivo que ele faz funcionar.

Retomando, pois, o célebre adágio popular, se "imagens falam mais do que mil palavras", o que dizer desse momento em que imagens, palavras (escritas, orais) e tantos outros "tecnoelementos" se juntam, interpenetram-se e colaboram para a constituição de sentidos argumentativos múltiplos e complexos? O desafio está lançado.

\section{REFERÊNCIAS}

AMOSSY, R. A argumentação no discurso. São Paulo: Contexto, 2020.

ANGENOT, M. Dialogues de sourds. Paris : Mille et une nuits/Fayard, 2008.

BRANDINO, G ; GALF, R; FERREIRA, F. Entenda potenciais crimes de Bolsonaro nos atos de 7 de Setembro e possíveis consequências. Folha de São Paulo, São Paulo, 8, set. 2021. FolhaJus. Disponível em: https://www1.folha.uol.com.br/poder/2021/09/entenda-os-potenciais-crimes-de-bolsonaro-nos-atos-do-7de-setembro.shtml?origin=uol. Acesso em: 14, set. 2021.

CHARAUDEAU, P. Uma teoria dos sujeitos da linguagem. In: MARI, H et alii. Análise do discurso: fundamentos e práticas. Belo Horizonte: Núcleo de Análise do Discurso -FALE/UFMG, 2001. p. 23-37.

CHAVES, E.S. Mulheres de direita, imprensa e o golpe de 1964: a "marcha" noticiada. Rev. Hist. UEG - Morrinhos, v.10, n.2, e-022104, jul./dez. 2021

GALLINARI, M. Hipóteses para uma análise discursiva das imagens. In: MENDES, E; MACHADO, I.L; LIMA, H; LYSARDO-DIAS, D (orgs.). Imagem e discurso. Belo Horizonte: FALE/UFMG, 2013, p. 355-369.

GILSTER, P. Digital literacy. New York: Wiley, 1997.

GREIMAS, Algirdas J. De l'imperfection. Périgueux: Pierre Fanlac, 1987.

KRESS, G; VAN LEEUWEN, T. Multimodal discourse: the modes and media of contemporary communication. London: Arnold, 2001.

LARA, G. Entre o sincrético e o visual : uma análise de publicidade chinesas. In: MENDES, E; MACHADO, I.L; LIMA, H; LYSARDO-DIAS, D (orgs.). Imagem e discurso. Belo Horizonte: FALE/UFMG, 2013, p. 194-216.

MENDES, E. Análise do discurso e iconicidade: uma proposta teórico-metodológica. In: MENDES, E; MACHADO, I.L; LIMA, H; LYSARDO-DIAS, D (orgs.). Imagem e discurso. Belo Horizonte: FALE/UFMG, 2013, p. 125-156.

MERZEAU, L. Du signe à la trace, ou l'information sur mesure. Hermès, Paris, n. 53, p. 23-29, 2009. DOI https://doi.org/10.4267/2042/31471.

MEYER, M. Principia rhetorica: une théorie générale de l'argumentation. Paris : Fayard, 2008. 


\section{REVISTA DA ABRALIN}

MOIRAND, S. L'événement «saisi » par la langue et la communication. Cahiers de Praxématique, Montpellier, n. 63, p. 1-25, 2014. DOI : https://doi.org/10.4000/praxematique.2362.

MOTTA, Rodrigo Patto Sá. Em guarda contra o 'Perigo Vermelho': o anticomunismo no Brasil (1917-1964). São Paulo: Perspectiva/Fapesp, 2002.

PAVEAU, M.A. Os pré-discursos: sentido, memória, cognição. Campinas/SP: Pontes Editores, 2013.

PAVEAU, M.A. Análise do discurso digital: dicionário das formas e das práticas. Campinas/SP: Pontes Editores, 2021.

PERELMAN, C; OLBRECHTS-TYTECA, L. Tratado da argumentação: a nova retórica. São Paulo: Martins Fontes, 2005.

RATO. In: DICIONÁRIO eletrônico Houaiss de Língua Portuguesa. Rio de Janeiro: Objetiva, 2021. Disponível em: https://houaiss.uol.com.br/corporativo/apps/uol_www/v5-4/html/index.php\#1. Acesso em: 15 ago. 2021.

SEIXAS, R. Entre a retórica do impeachment e a do golpe: análise de lógicas argumentativas na doxa política brasileira. Tese (Doutorado em Estudos Linguísticos) - Faculdade de Letras, Programa de Pós-Graduação em Estudos Linguísticos, Universidade Federal de Minas Gerais, Belo Horizonte, 2019.

SEIXAS, R; NASCIMENTO, L. Impeachment ou morte: a configuração retórica de um evento polemico no espaç, público digital. Rev. Estud. Ling., Belo Horizonte, v. 29, n. 4, p. 2397-2428, 2021. DOI: http://dx.doi.org/10.17851/2237-2083.29.4.2397-2428.

ZAPPAVIGNA, M. Searchable Talk: The Linguistic Functions of Hashtags. Social Semiotics, [S.l.], v. 25, n. 3, p. 1-18, 2015. DOI: $\underline{\text { http://dx.doi.org/10.1080/10350330.2014.996948. }}$. 